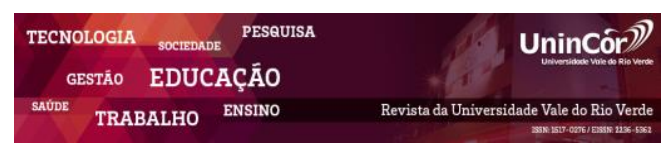

Revista da Universidade Vale do Rio Verde ISSN: 1517-0276 / EISSN: 2236-5362 v. $16\left|n^{\circ} .3\right|$ Ano 2018

Thaila Karoline da Silva Universidade Vale do Rio Verde (UninCor) Thailaagro2017@gmail.com

Bruno Gonçalves Borges Universidade Vale do Rio Verde (UninCor) brunno_borges.tc@hotmail.com

Aurivan Soares de Freitas Universidade Vale do Rio Verde (UninCor) aurivan.soares@hotmail.com

Maria Gilmara de Oliveira Soares Universidade Federal de Lavras (UFLA) gilmaraagronomia@gmail.com

Elaine Jamires Freitas

Universidade Vale do Rio Verde (UninCor) elainejamires@hotmail.com

Eliana Alcantra

Universidade Vale do Rio Verde (UninCor) prof.eliana.alcantra@unincor.edu.br

Júnia Rafael Mendonça Figueiredo Universidade Vale do Rio Verde (UninCor) prof.junia.figueiredo@unincor.edu.br

\section{ATIVIDADE ANTIFÚNGICA IN VITRO DE PRÓPOLIS SOBRE Colletotrichum spp. DO ABACATE}

\begin{abstract}
RESUMO
O abacate é um fruto de alto valor nutricional rico em vitaminas, proteínas e sais minerais. Entretanto, sua produção é afetada por doenças pós-colheita, sendo a principal delas a antracnose causada por fungos do gênero Colletotrichum. Assim, objetivouse com esse trabalho avaliar o efeito de própolis no crescimento micelial e na germinação de conídios de Colletotrichum spp. Foram testadas cinco doses de própolis: 0, 0,5, 1,0, 1,5 e 2,0 mL $\mathrm{L}^{-1}$. Para a montagem dos ensaios, preparou-se os meios de cultura batata dextrose ágar (BDA) e ágar-água (AA), em seguida, foi incorporado nos mesmos as concentrações de própolis. $\mathrm{O}$ meio contendo própolis foi vertido em placas de Petri de $9 \mathrm{~cm}$ de diâmetro. Após solidificação, foi transferido para placas disco de micélio ( $5 \mathrm{~mm}$ de diâmetro) e alíquota de $100 \mu \mathrm{L}$ de conídios para avaliar o crescimento micelial e a germinação de conídios, respectivamente. As avaliações do crescimento micelial foram transformadas em índice de velocidade crescimento micelial (IVCM). O incremento das concentrações de própolis de 0,5 para $2 \mathrm{~mL} \mathrm{~L}^{-1}$ reduziu o IVMC e a porcentagem de germinação de conídios. O maior IVCM $(10,05)$ e a maior porcentagem de germinação (96\%) foram encontrados na concentração de $0 \mathrm{~mL} \mathrm{~L}$ ${ }^{1}$ de própolis.
\end{abstract}

Palavras-Chave: Antracnose. Persea americana Mill. Póscolheita. Controle alternativo. Fungicida.

\section{IN VITRO ANTIFUNGAL ACTIVITY OF PROPOLIS IN Colletotrichum spp. OF AVOCADO}

\begin{abstract}
Avocado is a fruit of high nutritional value rich in vitamins, proteins and minerals. However, its production is affected by post-harvest diseases, the main one being the anthracnose caused by fungi of the genus Colletotrichum. Thus, the objective of this study was to evaluate the effect of propolis on mycelial growth and on conidial germination of Colletotrichum spp. Five doses of propolis were tested: $0,0.5,1.0,1.5$ and $2.0 \mathrm{~mL} \mathrm{~L}^{-1}$. To assay the assays, potato-dextrose agar (PDA) and Agar-Water (AW) were prepared, then the concentrations of propolis were incorporated therein. It was then poured into $9 \mathrm{~cm}$ diameter Petri dishes. After solidification, the mycelial disc plates $(5 \mathrm{~mm}$ diameter $)$ and 100 $\mu \mathrm{L}$ aliquot were transferred to the mycelial growth and conidial germination, respectively. The mycelial growth evaluations were transformed into mycelial growth rate index (MGRI). The increase of propolis concentrations of 0.5 to $2 \mathrm{~mL} \mathrm{~L}^{-1}$ reduced the MGRI and the percentage of conidia germination. The highest MGRI (10.05) and the highest percentage of germination (96\%) were found in the concentration of $0 \mathrm{~mL} \mathrm{~L}^{-1}$ of própolis.
\end{abstract}

Keywords: Anthracnose. Persea Americana Mill. Post-harvest. 


\section{INTRODUÇÃO}

O abacateiro (Persea americana Miller), pertencente à família Lauraceae, é originário do continente americano, mas apresenta como centro de diversidade o México e a Guatemala. É uma árvore frutífera tropical, rica em vitaminas, proteínas, lipídeos, fibras solúveis, fitoesteróis e minerais como ferro, cálcio e fósforo (FISCHER et al., 2017).

No Brasil, abacaticultura se desenvolveu a partir de 1970, sendo que em 2017 foi produzido 213.041 toneladas de abacates, em cerca de 13.019 hectares (IBGE, 2018). Em São Paulo, o abacateiro é cultivado em praticamente todos os municípios, concentrando-se em pequenas ou médias propriedades, com área entre 10 e 100 ha (FRANCISCO \& BAPTISTELLA, 2005).

O abacateiro é afetado por diversas doenças, que podem ser de origem fúngica, bacteriana, virótica ou causada por nematoides. Essas doenças resultam em perdas significativas na produtividade e na qualidade de frutos (PEGG et al., 2002).

Dentre as doenças que podem afetar o abacateiro, destaca-se a antracnose causada por espécies do gênero Colletotrichum (PICCININ et al., 2016), sendo essa a doença pós-colheita mais frequente do abacate no Brasil (TOZZE JÚNIOR et al., 2016).
A antracnose afeta principalmente os frutos, podendo ocorrer nas folhas, flores e ramos. Nos frutos, os sintomas iniciam-se por pequenas pontuações de coloração marrom a preta, que tendem a evoluir, atingindo parte do fruto, ou necrosando-o completamente, podendo ocorrer tanto no período pré como pós-colheita (BARBOSA et al., 2015; PEGG et al., 2002). Dessa forma, a doença causa prejuízos econômicos aos produtores, e diminui o acesso da população a este produto que, por sua vez, é comum na mesa dos brasileiros e também comercializado em escala mundial, sendo necessário realizar o controle fitossanitário.

O controle da antracnose é realizado ainda no campo, por meio de adubação equilibrada e aplicação de fungicidas. Além disso, devem ser empregadas outras estratégias de manejo em pós-colheita, como uso de embalagens apropriadas e cuidado durante $o$ transporte (CRUZ et al., 2010).

A aplicação de fungicidas é realizada duas à três vezes no pomar entre o florescimento e a frutificação (PEGG et al., 2002). No entanto, essa prática além de favorecer o desenvolvimento de resistência dos patógenos, provoca risco de contaminação ao ambiente e ao homem (CRUZ et al., 2010). Dessa forma, estudos têm buscado formas alternativas de controle dessa doença. Dentre essas alternativas, destaca-se a aplicação de própolis, visto que é um produto com propriedades antifúngicas, devido à presença de várias substâncias como os 
flavonoides (BARBOSA et al., 2015; MARINI et al., 2012).

No entanto, até o presente momento, estudos que objetivaram avaliar o efeito de própolis no crescimento micelial e na germinação de conídios de Colletotrichum spp. do abacateiro são escassos. Diante da necessidade de maiores informações sob medidas de controle alternativo da antracnose do abacateiro, objetivou-se com esse trabalho avaliar o potencial in vitro de própolis no crescimento micelial e na germinação de conídios de Colletotrichum spp.

\section{MATERIAL E MÉTODOS}

$\mathrm{O}$ experimento foi conduzido in vitro nos Laboratórios de Microbiologia e Pesquisa I da Universidade Vale do Rio Verde (UninCor), campus de Três Corações, Minas Gerais.

\subsection{Obtenção do isolado}

Colletotrichum spp. foi isolado a partir de frutos de abacateiro. Pequenos fragmentos lesionados foram desinfestados em álcool $70 \%$ por 30 segundos, hipoclorito de sódio a $2 \%$ por 1 minuto, lavados com água destilada e esterilizada por três vezes e secos em papel de filtro esterilizado. Em seguida, os fragmentos foram transferidos para placas de Petri, contendo meio de cultura Batata Dextrose Ágar - BDA $(9,75 \mathrm{~g}$ de BDA, 20 g de ágar e $1.000 \mathrm{~mL}$ de água destilada) e mantidos em câmara de crescimento (BOD) a $25^{\circ} \mathrm{C}$ com fotoperíodo de 12 horas.

\subsection{Avaliação do crescimento micelial de Colletotrichum spp.}

O crescimento micelial foi avaliado em placas de Petri contendo meio de cultura BDA e própolis. A própolis (Tintura de própolis ${ }^{\circledR}$ ) foi adicionado ao meio, nas concentrações de $0 ; 0,5$; 1,$0 ; 1,5 ; 2,0 \quad \mathrm{~mL} \mathrm{~L} \mathrm{~L}^{-1}$, constituindo cinco tratamentos e quatro repetições. Cada repetição constituiu por uma placa de Petri. Em seguida, o meio de cultura foi vertido em placas de Petri com $9 \mathrm{~cm}$ de diâmetro. Após a solidificação do meio de cultura, foi depositado no centro de cada placa um disco de micélio ( $5 \mathrm{~mm}$ de diâmetro) do fungo. Logo após, as placas foram vedadas com papel filme e incubadas em BOD a $25^{\circ} \mathrm{C}$, com fotoperíodo de 12 horas.

As avaliações foram realizadas, diariamente, durante sete dias, medindo-se com paquímetro o diâmetro das colônias em dois sentidos, de forma ortogonal. $O$ índice de velocidade crescimento micelial (IVCM) foi calculado pela fórmula proposta por Maguire (1962) e adaptada por Oliveira (1991): IVCM= $\sum(\mathrm{D}-\mathrm{Da}) / \mathrm{N} . \quad$ Em que: IVCM= índice de velocidade de crescimento micelial; $\sum=$ somatório; $\mathrm{D}=$ diâmetro médio atual; $\mathrm{Da}=$ diâmetro médio do dia anterior e $\mathrm{N}=$ número de dias após a deposição do micélio.

\subsection{Avaliação da germinação de conídios de} Colletotrichum spp.

Para obter conídios, adicionaram-se 10 $\mathrm{mL}$ de água destilada esterilizada, em cada placa de Petri e com bastão de vidro, previamente, esterilizado procedeu-se à liberação dos conídios a partir do micélio seco. A suspensão obtida foi 
filtrada em gaze e a concentração ajustada para 2 x $10^{6}$, utilizando hemacitômetro, estabelecendose média de 4 leituras.

Foram utilizadas placas de Petri de $9 \mathrm{~cm}$ de diâmetro, com $9 \mathrm{~mL}$ de meio ágar-água fundente e $1 \mathrm{~mL}$ das concentrações: $0,0,5,1,0$, 1,5 e 2,0 $\mathrm{mL} \mathrm{L}^{-1}$ de própolis.

Após a solidificação do meio, em cada placa, foram depositadas alíquotas de $100 \mu \mathrm{L}$ da suspensão e espalhadas com alça de Drigalsky. Depois as placas foram vedadas com papel filme e incubadas em BOD a $25^{\circ} \mathrm{C}$, com fotoperíodo de 12 horas. Após 12 horas, as placas foram retiradas da BOD e a germinação dos conídios foi paralisada aplicando-se em cada placa duas gotas de lactoglicerol.

Em seguida, foi feita a contagem dos conídios germinados em microscópio óptico. Para cada repetição, foram contados 100 conídios, totalizando 400 conídios por tratamento. Considerou-se conídio germinado aquele que apresentou o comprimento do tubo germinativo maior ou igual ao diâmetro do conídio. Com o número total de conídios contados (germinados e não germinados), estimou-se a porcentagem de conídios germinados.

\subsection{Análise estatística}

Os dados foram submetidos à análise de variância a nível de $5 \%$ de probabilidade. As variáveis significativas foram submetidas ao ajuste de modelos de regressão. As análises foram realizadas utilizando o software Sisvar (FERREIRA, 2008).

\section{RESULTADOS E DISCUSSÃO}

\subsection{Crescimento micelial de Colletotrichum} spp.

O crescimento micelial de Colletotrichum spp. foi significativamente influenciado pela concentração de própolis no meio de cultura. A maior porcentagem de germinação (96\%) foi encontrada na ausência de própolis. O incremento das concentrações de própolis de 0,5 para $2 \mathrm{~mL} \mathrm{~L}^{-1}$ reduziu linearmente o índice de crescimento micelial. Dessa forma, pode-se observar que o crescimento da colônia foi inversamente proporcional à concentração de própolis aplicada (Figura 1).

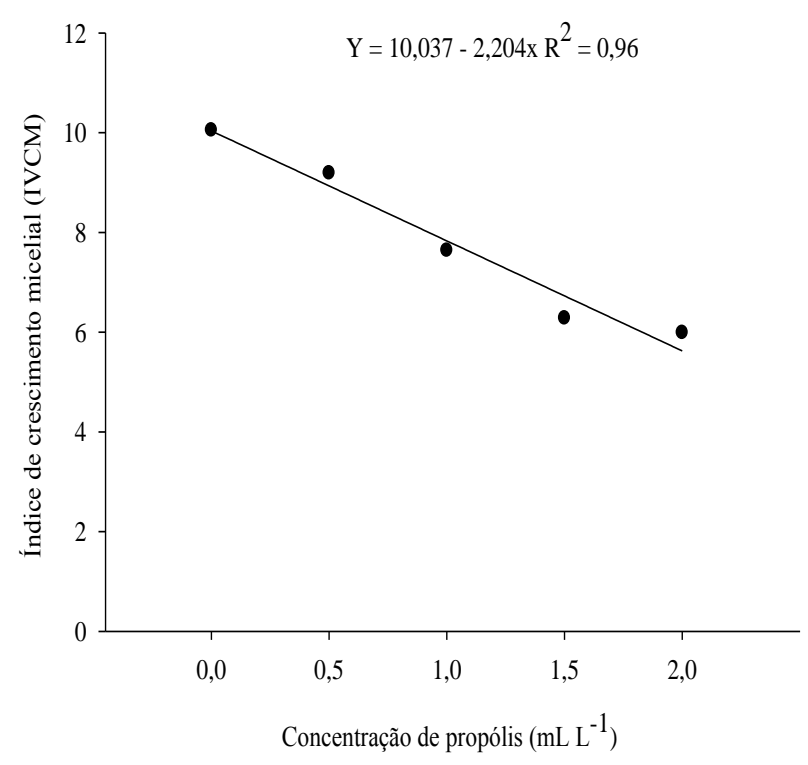

Figura 1 - Índice de crescimento micelial de Colletotrichum spp. com diferentes concentrações de própolis.

Resultados diferentes foram encontrados em outros trabalhos. Barbosa et al. (2015) constataram baixa influência de própolis sob $C$. musae da banana. Machado et al. (2015), também relataram baixa eficiência de 
própolis sobre Lasiodiplodia theobromae e $C$. gloesporioides da manga. Para Barbosa et al. (2015), a divergência na eficiência de própolis deve-se em parte a sua origem, pois essa substância possui composição química complexa que estar relacionada com a flora fornecedora de recursos às abelhas (MARCUCCI, 1995).

\subsection{Germinação de conídios de Colletotrichum}

spp.

A germinação de conídios de Colletotrichum spp. foi significativamente influenciada pela concentração de própolis no meio de cultura. A maior porcentagem de germinação (99\%) foi encontrada na ausência de própolis, corroborando com os dados de crescimento micelial de Colletotrichum spp. obtidos nesse trabalho, o que afirma a eficiência da própolis em inibir o crescimento desse fungo. $\mathrm{O}$ incremento das concentrações de própolis de 0,5 para $2 \mathrm{~mL} \mathrm{~L}^{-1}$ reduziu linearmente a porcentagem de germinação de conídios, sendo que na maior concentração houve redução de 96\% na redução da germinação (Figura 2).

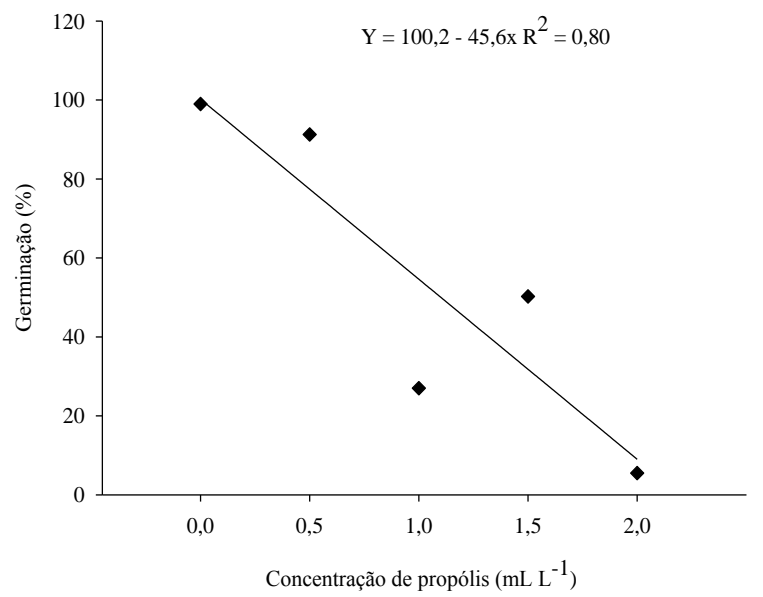

Figura 2 - Porcentagem de germinação de Colletotrichum spp. em diferentes concentrações de própolis.
Resultados semelhantes a esse foram encontrados quando a própolis foi utilizada para inibição da germinação de urediniosporos de Hemileia vastatrix, agente etiológico da ferrugem no cafeeiro. Nesse trabalho, a partir da concentração de $1 \mathrm{~mL} \mathrm{~L}^{-1}$ a germinação dos esporos foi fortemente inibida, chegando a inibir aos $2,0 \mathrm{~mL} \mathrm{~L} \mathrm{~L}^{-1} 99 \%$ germinação dos esporos (PEREIRA et al., 2007). Esses resultados demonstram o potencial antifúngico da própolis, podendo ser eficiente no controle pós-colheita da antracnose em abacate.

\section{CONCLUSÃO}

A maior dosagem de própolis promoveu o menor índice de crescimento micelial e a menor germinação de conídios, apresentando potencial de controle in vitro de Colletotrichum spp.

\section{REFERÊNCIAS}

BARBOSA, M. S.; VIEIRA, G.H.C.; TEIXEIRA, A. V. Atividade biológica in vitro de própolis e óleos essenciais sobre o fungo Colletotrichum musae isolado de bananeira (Musa spp.). Revista Brasileira de Plantas Medicinais. v.17, n. 2, pp. 254-261, 2015.

CRUZ, M. J. D. S.; CLEMENTE, E.; CRUZ, M. E. D. S.; MORA, F.; COSSARO, L.; PELISSON, N. Effects of bioactive natural compounds on the postharvest conservation of mango fruits cv. Tommy Atkins. Ciência e Agrotecnologia, v. 34, n. 2, pp. 428-433, 2010.

FERREIRA, D. F. Sisvar: um programa para análises e ensino de estatística. Ciência agrotecnologia. v. 35, n. 6, 2011 .

FISCHER, I.; MORAES, M.; PALHARINI, M.; CRUZ, J.; FIRMINO, A. Ocorrência de antracnose em abacate, agressividade e sensibilidade de Colletotrichum gloeosporioides a fungicidas.

Agropecuária Científica no Semiárido, v. 13, n. 2, p.130-137, 2017. 
FRANCISCO, V. L. F. S.; BAPTISTELLA. C. S. L. Cultura do abacate no estado de São Paulo.

Informações Econômicas, v. 35, n. 5, p. 27-41, 2005.

\section{INSTITUTO BRASILEIRO DE GEOGRAFIA E} ESTATÍSTICA - IBGE. Lavoura permanente. 2017. Disponível em:

<http://www.ibge.gov.br/estadosat/temas.php?sigla=sp \&tema=lavourapermanente2017>. Acesso em: 22 nov. 2018.

MACHADO, P. P.; VIEIRA, G. H. C.; MACHADO, R. A. Uso da própolis e óleo de nim no controle dos fungos Lasiodiplodia theobromae e Colletotrichum gloesporioides: principais patógenos que acometem os frutos da manga. Revista de Agricultura

Neotropical, v. 2, n. 4, p. 31-37, 2015.

MAGUIRE, J. D. Speed of germination: aid in selection and evaluation for seedling emergence and vigour. Crop Science, v. 2, n. 2, 1962.

MARINI, D.; MENSCH, R.; FREIBERGER, M. B.; DARTORA, J.; FRANZENER, G.; GARCIA, R. C.; STANGARLIN, J. R. Efeito antifúngico de extratos alcoólicos de própolis sobre patógenos da videira. Arquivos do Instituto Biológico, São Paulo-SP, v. 79, n. 2, p. 305-308, 2012.

MARCUCCI, M. C. Propolis: chemical composition, biological properties and therapeutic activity.

Apidologie, v. 26, n. 1, p. 83-99, 1995.

PEGG, K. G.; COATES, L. M.; KORSTEN, L.; HARDING, R. M. Foliar, fruit and soilborne diseases. In: The Avocado: Botany, Production and Uses. Whiley A.W., Schaffer B. and Wolstenholme B. N. (eds): CAB International, Wallingford, UK, pp. 299338, 2002.

PEREIRA, C. S.; CARVALHO, S. J. D.; GUIMARÃES, R. J.; POZZA, E. A. Extrato etanólico de própolis (EEP) na inibição da germinação de urediniosporos da ferrugem do cafeeiro Hemileia vastatrix Berk e Cooke, 2007.

OLIVEIRA, J. A. Efeito do tratamento fungicida em sementes e no controle de tombamento de plântulas de pepino (Cucumis sativus L.) e pimentão (Capsicum annum L.). Dissertação (Mestrado - área de Concentração em Fitossanidade) Departamento de Fitossanidade, Universidade Federal de Lavras, Lavras, MG, p. 111, 1991.

PICCININ, E.; PASCHOLATE, R. M.; DI PIERO, R. M., BENATO, E. A. Doenças do abacateiro. In: AMORIM, L. et al. (Ed.). Manual de fitopatologia. 5. ed. Ouro Fino - MG: Agronômica Ceres, p. 1-7, 2016.
TOZZE JÚNIOR, H. J. T.; FIRMINO, A. C. FISCHER, I. H.; FURTADO, E. L.; MASSOLA, N. S. Caracterização da agressividade e atividade enzimática de isolados de Colletotrichum spp. associados à antracnose do abacate. Summa Phytopathologica, Botucatu, v. 42, n. 3, p. 264-267, 2016.

\section{Thaila Karoline da Silva}

Bacharel em Agronomia pela Universidade Vale do Rio Verde (UninCor), Três Corações, Minas Gerais.

\section{Bruno Gonçalves Borges}

Bacharel em Agronomia pela Universidade Vale do Rio Verde (UninCor), Três Corações, Minas Gerais.

\section{Aurivan Soares de Freitas}

Mestre e doutor em Fitopatologia pela Universidade Federal de Lavras (UFLA). Professor na Universidade Vale do Rio Verde (UninCor).

Maria Gilmara de Oliveira Soares
Mestre e doutoranda em Fitopatologia pela
Universidade Federal de Lavras (UFLA).

\section{Elaine Jamires Freitas}

Graduanda em Agronomia pela Universidade Vale do Rio Verde (UninCor). Três Corações, Minas Gerais.

\section{Eliana Alcantra}

Mestre e doutora em Entomologia pela Universidade Federal de Lavras (UFLA). Professora na Universidade Vale do Rio Verde (UninCor).

Júnia Rafael Mendonça Figueiredo
Mestre e doutora em Fisiologia Vegetal pela
Universidade Federal de Lavras (UFLA). Professora
na Universidade Vale do Rio Verde (UninCor).

